\title{
Induction of Immunogenic Response in BALB/c Mice by Live and Killed Form of Recombinant Lactococcus lactis Displaying EG95 of Echinococcus granulosus
}

\author{
Fatemeh Ebrahimzadeh ${ }^{1}$, Hoda Shirdast ${ }^{1}$, Amirhossein Taromchi ${ }^{1,5^{*}}$, Yeganeh Talebkhan ${ }^{2}$, \\ Ali Haniloo ${ }^{3}$, Abdolreza Esmaeilzadeh ${ }^{4,5}$, Keivan Nedaei ${ }^{1}$ and Esmat Mirabzadeh ${ }^{6}$ \\ ${ }^{1}$ Department of Medical Biotechnology, Faculty of Medicine, Zanjan University of Medical Sciences, Zanjan, \\ Iran; ${ }^{2}$ Biotechnology Research Center, Pasteur Institute of Iran, Tehran, Iran; ${ }^{3}$ Department of Medical \\ Parasitology and Mycology, Faculty of Medicine, Zanjan University of Medical Sciences, Zanjan, Iran; \\ ${ }^{4}$ Department of Immunology, Faculty of Medicine, Zanjan University of Medical Sciences, Zanjan, Iran; \\ ${ }^{5}$ Cancer Gene Therapy Research Center, Zanjan University of Medical Sciences, Zanjan, Iran; ${ }^{6}$ Department \\ of Molecular Medicine, Biotechnology Research Center, Pasteur Institute of Iran, Tehran, Iran
}

Received 15 December 2020; accepted 4 January 2021; published online 30 June 2021

\begin{abstract}
Background: CE is a zoonotic parasitic infection caused by Echinococcus granulosus worldwide and is associated with economic losses among livestock animals. EG95 is an immunogenic antigen from the E. granulosus. Lactococcus lactis has been prested as a safe vehicle for antigen delivery. The goal of this study was to design a novel L. lactis strain displaying EG95 as a vaccine delivery system. Methods: The eg95 encoding gene fragment fused to the M6 anchoring protein was cloned into the pNZ7021 vector, and L. lactis NZ9000 displaying recombinant EG95 was constructed. The expression of an approximately 32-kDa EG95 protein was confirmed by Western blotting and immunofluorescence analysis. The immune responses were evaluated in BALB/c mice immunized orally and subcutaneously with the live and killed recombinant L. lactis, respectively. Results: Total IgG level in mice immunized with heat-killed recombinant L. lactis (pNZ7021-eg95) significantly increased compared to the control group. slgA was significantly higher in mice received live recombinant L. lactis (pNZ7021-eg95) compared to the control mice. Splenic lymphocytes from immunized mice represented the high levels of IFN- $\gamma$ and the low-levels of IL-4 and IL-10. Conclusion: Our results indicate that immunization with EG95-expressing $L$. lactis can induce both specific humoral and cellular immune responses in mice. DOI: 10.52547/ibj.25.4.284
\end{abstract}

Keywords: Echinococcus granulosus, Lactococcus lactis, Immunization, Vaccines

Corresponding Author: Amirhossein Taromchi

Department of Medical Biotechnology, Faculty of Medicine, Zanjan University of Medical Sciences, Zanjan, Iran;

Tel: (+98-24) 33140235; fax: (+98-24) 33 449553; Email: taromchi@zums.ac.ir, taromchi@yahoo.com

\section{INTRODUCTION}

$\mathrm{C}$ ystic echinococcosis is a zoonotic infection caused by metacestode stage of the parasitic tapeworm, Echinococcus granulosus ${ }^{[1]}$. Two types of mammalian hosts are involved in the parasite's life cycle. The definitive hosts are canids in which adult tapeworms can be developed in the small intestine, and the intermediate hosts are ungulates, including livestock (especially sheep), which are infected by the intake of the parasite eggs excreted in the feces of infected dogs and other canids. In addition,

List of Abbreviations:

CE, cystic echinococcosis; Con A, concanavalin A; HRP, horseradish peroxidase; LAB, lactic acid bacteria; MTT, 3(4,5dimethylthiazole-2yl)-2,5 diphenyl tetrazolium bromide; RT, room temperature; slgA, mucosal IgA; TBST, Tris-buffered saline, $0.1 \%$ Tween 20 
humans can be accidentally infected through the exposure to the parasite eggs. The ingested eggs hatch and release oncospheres that pass through the intestinal mucosa and frequently reach the liver and lungs via the portal and lymphatic vessels. Finally, they can develop as hydatid cysts in which many protoscoleces are produced asexually. When infected livestock offal is consumed by dogs or other canids, each protoscolex develops to an adult worm in the small intestine ${ }^{[2]}$.

The high prevalence of the CE in many areas of the world influences public health and is considered as a main factor for remarkable economic losses among livestock animals, particularly in highly endemic regionss $^{[3]}$. Currently, the control of $\mathrm{CE}$ mainly depends on the disposal of the infected offal, preventing $\operatorname{dog} s$ from feeding on infected livestock viscera and periodic treatment of dogs with praziquantel $^{[4]}$. Moreover, vaccination of sheep has been recommended as a complementary and effective approach to control $\mathrm{CE}$ transmission by interrupting the tapeworm life cycle $\mathrm{e}^{[5-8]}$

Several vaccine candidate antigens have been tested for the immunization against $E$. granulosus ${ }^{[9-11]}$. Among them, EG95 is considered as a protective antigen against CE in sheep. EG95 is developed as a recombinant vaccine and induces the high levels of protection (96-100\%), when used as a vaccine in sheep as an intermediate host in New Zealand, Australia, and Argentina $^{[7,8]}$.

Probiotics are described as live bacteria having beneficial and positive influences on human beings and animal health. Accordingly, most of them are LAB, which are G-positive, non-colonizing, nonpathogenic, and food-grade microorganisms and mainly were exploited in the food industry for manufacturing fermented products due to a long history of their safe status $^{[12]}$. LAB are normal microorganisms of the gastrointestinal tract, considered as "generally regarded as safe" with positive impact on the immune and digestion system $^{[12-14]}$. Moreover, different LAB strains have been used as a safe expression system for the production and delivery of various proteins to treat diseases such as cervical cancer, diabetes, obesity, and inflammatory bowel diseases ${ }^{[15-18]}$. LAB can also be utilized as a live vector to deliver heterologous proteins to the mucosal surfaces, for vaccination and biomedical applications $^{[19-21]}$.

Attractive and beneficial biological properties of LAB, including immunomodulatory and immunostimulation effects without inducing side effects, besides the adjuvanticity, ease of production, and suitable oral administration route, make them advantageous and effective candidates for vaccine development $^{[22,23]}$. Therefore, several LAB such as $L$. lactis have been extensively exploited as a safe vehicle for the expression and delivery of foreign antigens, and their immunogenicity was evaluated for the development of vaccines against different infections ${ }^{\text {[24- }}$ 26]

In most endemic developing countries, the production process and vaccination costs of sheep with the recombinant EG95 vaccine may prevent the vast utilization of the vaccine. Thus, in this study, we constructed a recombinant L. lactis NZ9000 to express surface displayed EG95 protein using the M6 cell wall anchor. The immune responses were evaluated by the immunization of $\mathrm{BALB} / \mathrm{c}$ mice with live and heatkilled form of the recombinant $L$. lactis displaying EG95.

\section{MATERIALS AND METHODS}

\section{Bacterial strains, media, and growth conditions}

L. lactis NZ9000 (MoBiTec, Germany) was cultivated at $30{ }^{\circ} \mathrm{C}$ without shaking in M17 broth (Quelab, Canada) supplemented with $0.5 \%$ (w/v) glucose (GM17) and $10 \mu \mathrm{g} / \mathrm{ml}$ of chloramphenicol (Bio Basic, Canada). Escherichia coli TOP10 was cultured in Luria-Bertani medium (Sigma-Aldrich, USA) containing appropriate antibiotic (Bio Basic) on a shaker incubator at $37^{\circ} \mathrm{C}$ for $16 \mathrm{~h}$.

\section{Gene synthesis}

A 972-bp gene fragment encoding the precursor protein $\mathrm{SP}_{\mathrm{Usp} 45}-\mathrm{EG} 95-\mathrm{CWA}_{\mathrm{M} 6}$, composed of the Usp45 signal peptide (the native lactococcal secretion signal sequence) fused to the eg95 coding sequence (GeneBank accession number X90928.1). Subsequently, the cell wall anchor fragment of the Streptococcus pyogenes M6 protein fused at its Cterminus was designed by ApE software and codonoptimized for protein expression in L. lactis. Moreover, SphI and BanII restriction sites were added to $5^{\prime}$ and $3^{\prime}$ ends of this construct. The synthesis of the gene sequence was performed in $\mathrm{pGH}$ cloning vector by the Generay Biotechnology Company (Shanghai, China).

\section{Construction of the recombinant $L$. lactis}

The bacterial strains, plasmids and primers utilized in the present study are listed in Tables 1 and 2. The eg95 gene was PCR-amplified from the pGH-eg95 using M13 primers. The 1189-bp fragment was digested by BanII and SphI restriction enzymes (Thermo Fisher Scientific, USA), then was purified by CleanUp kit (GeneAll, Korea) and inserted into the BanII/ SphI double-digested pNZ7021 (MoBiTec) by T4 DNA ligase (Thermo Fisher Scientific), resulting in 
Table 1. Bacterial strains and plasmids used in this study

\begin{tabular}{|c|c|c|}
\hline Strain or plasmid & Description & Source or references \\
\hline E. coli TOP10 & Cloning host & Our lab \\
\hline E. coli TOP10-pGH & E. coli Top 10 containing $\mathrm{pGH}$ & This study \\
\hline L. lactis NZ9000 & MG1363 derivative, pepN::nisRK & {$[27]$} \\
\hline L. lactis (pNZ7021) & L. lactis containing empty vector pNZ7021 & This study \\
\hline L. lactis (pNZ7021-eg95) & L. lactis containing pNZ7021-eg95 & This study \\
\hline pGH-eg95 & pGH harboring eg95 gene & Generay Biotechnology \\
\hline pNZ7021 & $\begin{array}{l}\text { L. lactis expression vector, } \mathrm{Cm}^{\mathrm{R}} \text {, pNZ8148 derivative, pepN } \\
\text { promoter, } 3076 \mathrm{bp}\end{array}$ & [28] \\
\hline pNZ7021-eg95 & pNZ7021 harboring eg95 gene & This study \\
\hline
\end{tabular}

pNZ7021-eg95. L. lacis strain NZ9000 was transformed by electroporation using a Gene Pulser (Eppendorf, Germany) in 0.1-cm electroporation cuvette (adjustment: $2 \mathrm{kV}, 200 \Omega, 25 \mu \mathrm{F}$ ). Following the electric pulse, the G-M17 broth was added to the mixture and incubated at $30{ }^{\circ} \mathrm{C}$ for $3 \mathrm{~h}$. Finally, the NZ9000 transformants containing pNZ7021-eg95 were cultured on GM17 agar plates comprising $10 \mu \mathrm{g} / \mathrm{ml}$ of chloramphenicol and incubated at $30{ }^{\circ} \mathrm{C}$ for two days. Confirmation of the positive clones was performed by PCR utilizing PNZ primers. Extracted recombinant vectors were confirmed via restriction digestion and also sequencing.

\section{Polyclonal antibody production against the rEG95- GST protein}

Initially, $200 \mu \mathrm{g}$ of rEG95-GST protein emulsified with Quil A adjuvant (gifted by Prof. Lightowlers, Australia) was administered intradermally to a female white rabbit. After two weeks, a booster immunization dose $(200 \mu \mathrm{g})$ was given. Finally, two weeks later, the blood sample was obtained, and the serum sample was separated and stored at $-80^{\circ} \mathrm{C}$ for further assays.

\section{Expression and characterization of the EG95 protein}

To express EG95 in L. lactis, the NZ9000 transformants harboring pNZ7021-eg95 were cultivated. The cells were centrifuged at $11,000 \times \mathrm{g}$ for $10 \mathrm{~min}$, disrupted by sonication and applied for Western blotting. The suspension was lysed in a sample buffer, and the bacterial protein supernatants were loaded on $12 \%$ SDS-PAGE. After transferring the proteins onto a nitrocellulose membrane, blocking the membrane was carried out with $5 \%$ skim milk in trisbuffered saline, $0.1 \%$ Tween 20 (TBST) at $4{ }^{\circ} \mathrm{C}$ overnight. Then the membrane was treated with rabbit polyclonal serum at 1:500 dilution for $2 \mathrm{~h}$. The membrane was washed five times with TBST and incubated with 1:5000 HRP-conjugated goat anti-rabbit IgG secondary antibody (Sigma-Aldrich). Finally, color development was performed with DAB (SigmaAldrich).

\section{Immunofluorescence analysis}

L. lactis NZ9000 cells were cultivated, centrifuged at $2800 \times \mathrm{g}$ for $10 \mathrm{~min}$ and resuspended in PBS. The bacterial pellet was placed on Poly-L-lysine-coated glass slides and incubated at RT for $20 \mathrm{~min}$. The fixation of the slides was performed with $4 \%$ paraformaldehyde. Next, the cells were blocked with $4 \%$ BSA (Sigma-Aldrich) in PBS for $30 \mathrm{~min}$. The fixed cells were then incubated with 1:250 diluted rabbit anti-EG95 polyclonal serum at RT for $90 \mathrm{~min}$ and then washed three times with PBS. The slides were incubated with a 1:1000 FITC-conjugated goat antirabbit antibody (Sigma-Aldrich) for $90 \mathrm{~min}$ and washed three times with PBS at RT. Finally, the labeled slides were mounted with glycerol in PBS $(\mathrm{pH}$ 8.5-9.0) and then analyzed by immunofluorescence microscopy (Olympus, Japan).

\section{Mice immunization}

Pathogen-free female BALB/c mice (6-8 weeks old) were purchased from Razi Vaccine and Serum Research Institute (Iran), housed and acclimatized for one week in the Animal Care Facility Unit of Medicine in Zanjan University of Medical Sciences under a 12-h light/12-h dark schedule with free access to food and water. Mice were divided into seven groups $(\mathrm{n}=$ seven/group). Two groups of mice were orally immunized with $10^{10} \mathrm{CFU}^{[29,30]}$ of live L. lactis NZ9000 strains containing pNZ7021-eg95 vector, as the test group and L. lactis NZ9000 bacterium harboring pNZ7021 empty vector as a control group in $200 \mu \mathrm{l}$ of sterile PBS after fasting conditions for 8-10 h. As a negative control group, PBS was administered orally. For the oral administration, mice received eight treatments in four weeks. Two other groups were 
Table 2. Primers used in this study

\begin{tabular}{|c|c|c|c|}
\hline Primers & Forward $5^{\prime}$ to $3^{\prime}$ & Reverse $5^{\prime}$ to $3^{\prime}$ & Description \\
\hline M13 & GTTTTCCCAGTCACGAC & GCGGATAACAATTTCACACAGG & pGH gene construct \\
\hline PNZ & TGGGAATCATCACGTTCAGGT & GGCTATCAATCAAAGCAACACG & PNZ7021 ligation test \\
\hline
\end{tabular}

immunized subcutaneously with $10^{10} \mathrm{CFU}$ of heatkilled L. lactis NZ9000 strains on days 0, 14, and 28. The test and control groups were administered with heat-killed recombinant $L$. lactis containing pNZ7021eg95 vector and L. lactis with empty pNZ7021 vector, respectively. Killed bacteria were prepared by heating at $60{ }^{\circ} \mathrm{C}$ for $20 \mathrm{~min}$. As the positive and negative control groups, purified rEG95-GST protein $(20 \mu \mathrm{g})$ emulsified with Quil A adjuvant and PBS were administered subcutaneously to mice on days 0,14 , and 28. The mice were bled on day 0 (before immunization) for obtaining pre-immunized sera and two weeks after the last immunization. Blood samples were collected, and serum samples were separated and kept at $-80{ }^{\circ} \mathrm{C}$ for ELISA test. The animal experiment procedures are demonstrated in Figures 1 and 2 .

\section{Cytokine measurement and in vitro splenocyte proliferation assay}

Two weeks after the last immunization, five mice in each group were killed, and their spleens were aseptically removed. The splenocytes were isolated by single-cell suspension preparation via mechanical dissociation and homogenization. After red blood cells lysis by ACK solution $(150 \mathrm{mM} \mathrm{NH} 4 \mathrm{Cl}, 0.1 \mathrm{mM}$ Na2EDTA, $10 \mathrm{mM} \mathrm{KHCO3)}$ and three washes with PBS, the splenocytes were resuspended in RPMI 1640 medium (Inoclon, Iran) containing 10\% heatinactivated fetal bovine serum (Gibco, UK), $2 \mathrm{mM}$ of L-glutamine, $0.05 \mathrm{M}$ of 2-mercaptoethanol, and $1 \%$ penicillin-streptomycin (Sigma-Aldrich) and counted. Afterwards, $3 \times 10^{6}$ cells $/ \mathrm{ml}$ were plated with purified rEG95 (10 $\mu \mathrm{g} / \mathrm{ml})$, ConA ( $5 \mathrm{mg} / \mathrm{ml}$; Sigma-Aldrich), as the positive control and without any additive as a negative control and incubated with $5 \% \mathrm{CO}_{2}$ at $37{ }^{\circ} \mathrm{C}$ for $72 \mathrm{~h}$. The supernatants were then collected for the measurement of IFN- $\gamma$, IL-10, and IL-4 levels using available ELISA kits (R\&D Systems, USA) according to the manufacturer's protocols. The proliferative response of splenocytes was determined by MTT assay. After removing the supernatants, $20 \mu \mathrm{l}$ of MTT ( $5 \mathrm{mg} / \mathrm{ml}$; Sigma-Aldrich) was added to each well and incubated at $37^{\circ} \mathrm{C}$ for $4 \mathrm{~h}$. The plate was centrifuged at $1,000 \times \mathrm{g} 22{ }^{\circ} \mathrm{C}$ for $5 \mathrm{~min}$ and then was dissolved in $150 \mu \mathrm{l}$ of DMSO (Merck, Germany) at $37{ }^{\circ} \mathrm{C}$ for 20 min. The optical absorbance was measured at $570 \mathrm{~nm}$ with a reference wavelength of $630 \mathrm{~nm}$ by an ELISA microplate reader (BioTek, USA). Calculation of proliferative index as the definition of the proliferative responses was performed as follows: the average absorbance of the stimulated culture/the average absorbance of the non-stimulated culture.

\section{Determination of humoral immune responses by ELISA}

Mouse EG95-specific antibodies were determined using purified rEG95 as an antigen by ELISA. The 96well plates (Greiner Bio-One) were coated with 0.05 $\mathrm{ng} / \mathrm{ml}$ of purified rEG95 protein at $4{ }^{\circ} \mathrm{C}$ overnight. The plates were then washed three times with PBS

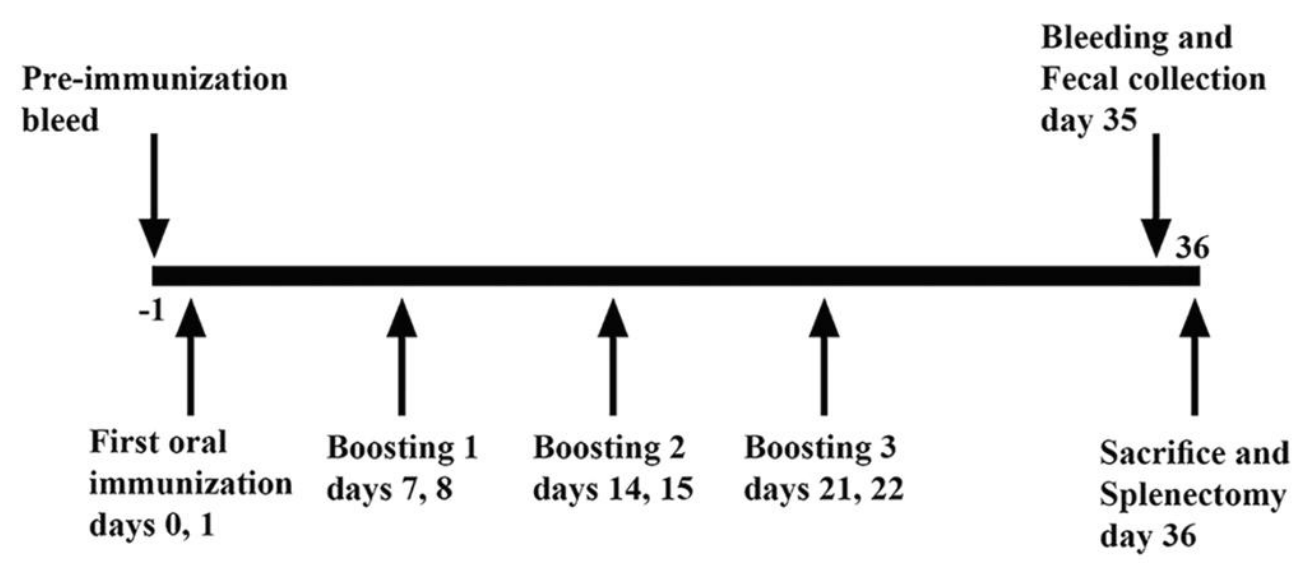

Fig. 1. Schematic representation of the oral immunization, serum, and fecal sampling schedule. Three groups of BALB/c mice were orally immunized on days 0 and 1 and received boosters on days 7 and 8, 14 and 15, and 21 and 22. Blood and fecal samples were collected on day 35 . The mice were sacrificed on day 36 . 


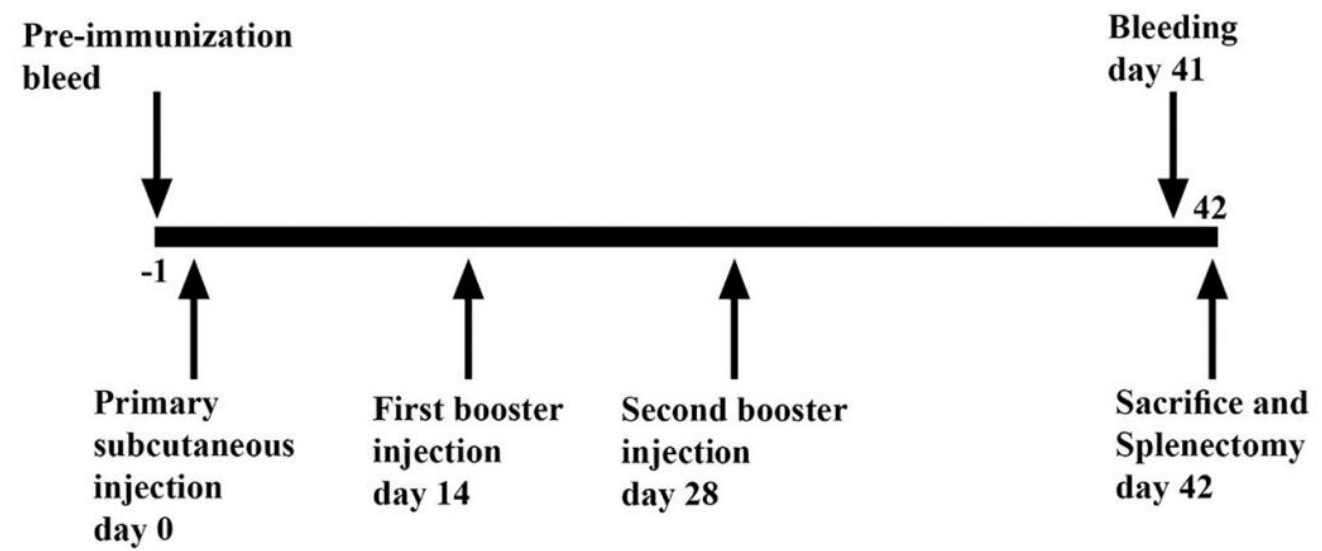

Fig. 2. Schematic representation of subcutaneous immunization and serum collection schedule. Four groups of BALB/c mice subcutaneously immunized on days 0,14 , and 28 . Blood samples were collected on day 41 . On day 42 , all the mice were sacrificed.

containing $0.05 \%$ Tween 20 (PBST) and blocked with PBS containing $1 \% \mathrm{BSA}$ at RT for $1 \mathrm{~h}$. After three washes with PBST, 1:200 dilution of serum samples $(100 \mu \mathrm{l} /$ well $)$ was added in duplicate as primary antibodies and incubated at RT $2 \mathrm{~h}$. The plates were washed three times with PBST. For total IgG assay, 1:1000 dilution of an HRP-conjugated polyclonal goat anti-mouse $\operatorname{IgG}$ (Bio-Rad) was added at RT for $1 \mathrm{~h}$.

Measurement of $\operatorname{IgG} 1, \operatorname{IgG} 2, \operatorname{IgG} 3, \operatorname{Ig} M$, and $\operatorname{Ig} \mathrm{A}$ antibodies was performed by adding $100 \mu \mathrm{l} /$ well of an anti-isotype monoclonal antibody (Sigma-Aldrich) specific for each antibody class for one hour. After washing the plates, 1:15000 HRP-conjugated rabbit anti-goat IgG (Sigma-Aldrich) was added to each well at RT for $1 \mathrm{~h}$. In each assay, after three times washing with PBST, $100 \mu \mathrm{l}$ of ABTS peroxidase substrate (KPL, SeraCare Life Sciences, USA) was added to each well, and the enzymatic reaction was stopped by the addition of $1 \%$ SDS. The optical absorbance was measured at $405 \mathrm{~nm}$ using an ELISA reader (BioTek). Fresh fecal pellets were collected two weeks after the last immunization from mice orally immunized with live L. lactis, resuspended in PBS containing 1\% BSA, and incubated at $4{ }^{\circ} \mathrm{C}$ overnight. The suspensions were vortexed, centrifuged at $18,000 \times \mathrm{g}$ at $4{ }^{\circ} \mathrm{C}$ for $10 \mathrm{~min}$, and the supernatants were used to measure sIgA levels using ELISA. Briefly, 96-well plates were coated with $0.1 \mathrm{ng} / \mathrm{ml}$ of purified rEG95 protein at $4{ }^{\circ} \mathrm{C}$ overnight. The plates were then washed three times with PBST, and the wells were blocked with BSA and incubated at RT for 1 hour. After washing three times with PBST, $100 \mu \mathrm{l}$ of fecal suspension was added to each well and incubated at RT for $2 \mathrm{~h}$. sIgA was detected using a goat monoclonal anti-mouse IgA and an HRP-conjugated rabbit anti-goat IgG (both from Sigma-Aldrich).

\section{Statistical analysis}

Statistical analysis of the data was accomplished using GraphPad Prism 8 (GraphPad, CA). The results were compared using one-way analysis of variance (ANOVA) and were represented as the mean \pm SD. The $p$ values $<0.05$ were considered as statistically significant levels.

\section{Ethical statement}

All animal handlings followed the ethical standards of the Animal Research Ethics Committee, Zanjan University of Medical Sciences, Zanjan, Iran (ethical code: ZUMS.REC.1396.64).

\section{RESULTS}

\section{Plasmid construction and expression of EG95 protein in L. lactis}

The graphic view of the pNZ7021-eg95 plasmid designed by SnapGene version 1.1.3 software (GSL Biotech LLC, CA, USA) is shown in Figure 3. The recombinant expression vector was verified by PCR amplification using PNZ primers, specifically designed for the flanking regions of the multiple cloning sites of plasmid backbone. The expected amplicon size was 1189 bp (Supplementary Fig. S1A). Restriction digestion also confirmed the cloning procedure (Supplementary Fig. S1B). Immunoblotting with polyclonal antiserum against purified rEG95-GST confirmed an approximately $33 \mathrm{kDa}$ protein consistent with the size of precursor $\mathrm{SP}_{\mathrm{Usp} 45^{-}} \mathrm{EG} 95-\mathrm{CWA} \mathrm{M}_{6}$, in the total protein extract of the recombinant $L$. lactis (Supplementary Fig. S1C).

\section{Surface expression of the EG95}

The immunofluorescence assay performed to confirm that recombinant L. lactis strain NZ9000 displayed 


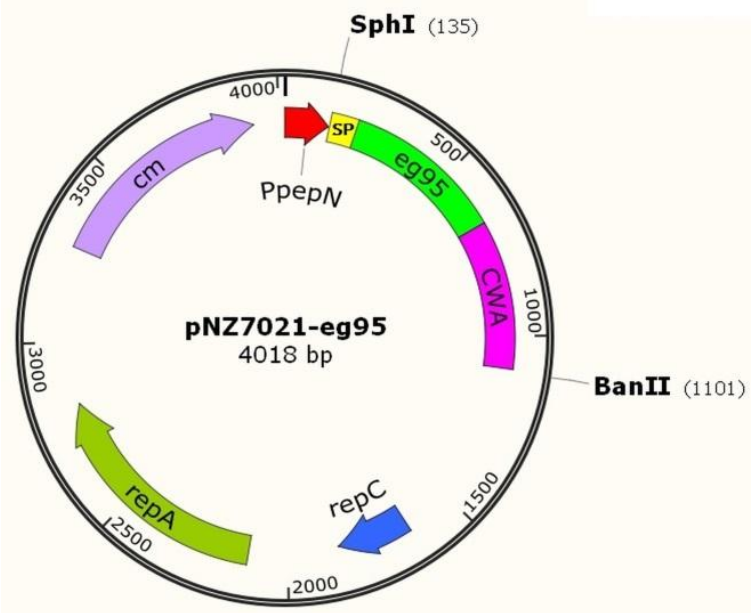

Fig. 3. The schematic view of the recombinant expression vector pNZ7021-eg95. PpepN, constitutive promoter; SP, Usp45 signal peptide sequence; eg95, eg95 gene coding sequence; CWA, M6 cell-wall anchor of Streptococcus pyogenes; rep C and rep A, replication gene $\mathrm{C}$ and $\mathrm{A}$, respectively; Chol, chloramphenicol resistance gene.

EG95 protein on the cell surface. Recombinant $L$. lactis NZ9000 (pNZ7021-eg95) cells revealed fluorescence (Fig. 4A), which was significantly different from the control strain NZ9000 (pNZ7021; Fig. 4B).

\section{Assessment of antibody responses}

sIgA levels in mice orally received live L. lactis (pNZ7021-eg95) was significantly higher than the mice immunized with live L. lactis (pNZ7021) and PBS control group ( $p<0.05$, Fig. 5). Assessment of total serum $\operatorname{IgG}$ levels in all tested groups is represented in Figure 6. The total IgG level in mice immunized with heat-killed recombinant $L$. lactis (pNZ7021-eg95) was significantly increased compared to those immunized with heat-killed $L$. lactis (pNZ7021) and PBS control group $(p<0.01)$. There were no significant differences of the live $L$. lactis (pNZ7021-eg95) and live L. lactis (pNZ7021) with the PBS control group for IgG production $(p>0.05)$. The mice immunized with the purified rEG95 showed a significant IgG response compared to the PBS control group ( $p<0.001)$. The assessment results of $\mathrm{IgG}$ subclasses (IgG1, IgG2a, IgG2a, and IgG3) demonstrated that the levels of $\operatorname{IgG} 1$ and $\operatorname{IgG} 2 \mathrm{a}$ antibodies increased, but no significant differences were observed for IgG subclasses between test and control groups ( $p>0.05$, Supplementary Fig. S2). Moreover, there were no significant differences between test and control groups for serum $\operatorname{IgA}$ and IgM isotypes ( $p>0.05$, data not shown).

\section{Proliferative responses of splenocytes}

As demonstrated in Figure 7, the mice immunized with killed and live recombinant L. lactis (pNZ7021eg95) demonstrated a significant $\mathrm{T}$-cell proliferative response compared to the mice immunized with killed and live L. lactis (pNZ7021) and PBS control group ( $p$ $<0.05)$. The mice immunized with purified rEG95 showed a significant $\mathrm{T}$-cell proliferative response compared to the PBS control group $(p<0.01)$.

\section{Cytokine assay}

The mice immunized with live and killed recombinant L. lactis (pNZ7021-eg95) showed the higher levels of IFN- $\gamma$ compared to the mice immunized with the live and killed L. lactis (pNZ7021) and PBS control group ( $p<0.05$, Fig. 8A). IFN- $\gamma$ levels in the mice immunized with purified rEG95 were significantly higher than those immunized with the PBS control group ( $p<0.01$, Fig. 8A). However, there were no significant differences between all test and control groups for the production of IL-10 and IL$4(p>0.05$, Fig. 8B and 8C).
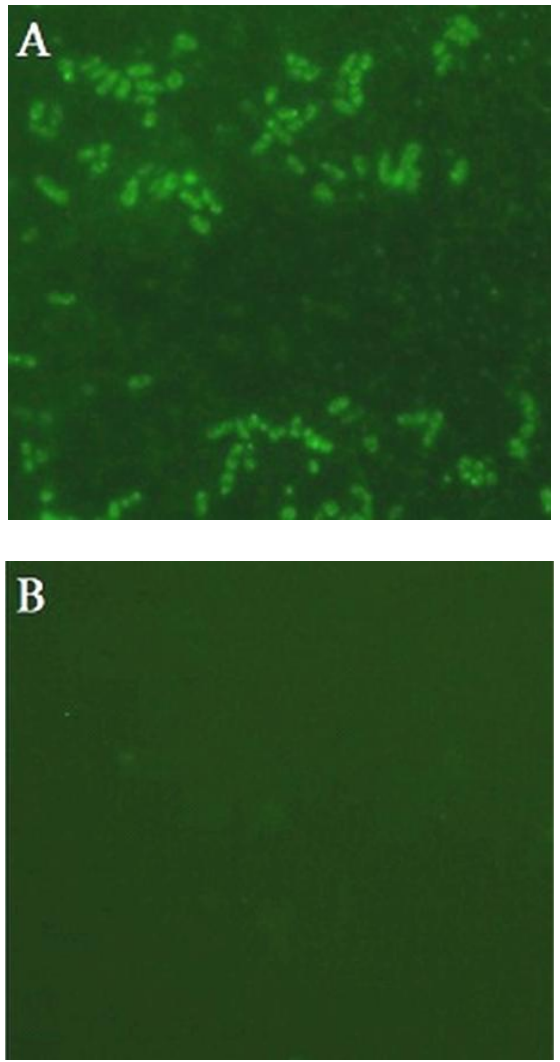

Fig. 4. Detection of recombinant EG95 protein on the surface of L. lactis by immunofluorescence analysis. (A) Recombinant L. lactis NZ9000 cells expressing EG95-CWA $\mathrm{M}_{\text {; }}$ (B) L. lactis NZ9000 cells containing empty pNZ7021 vector (negative control). 


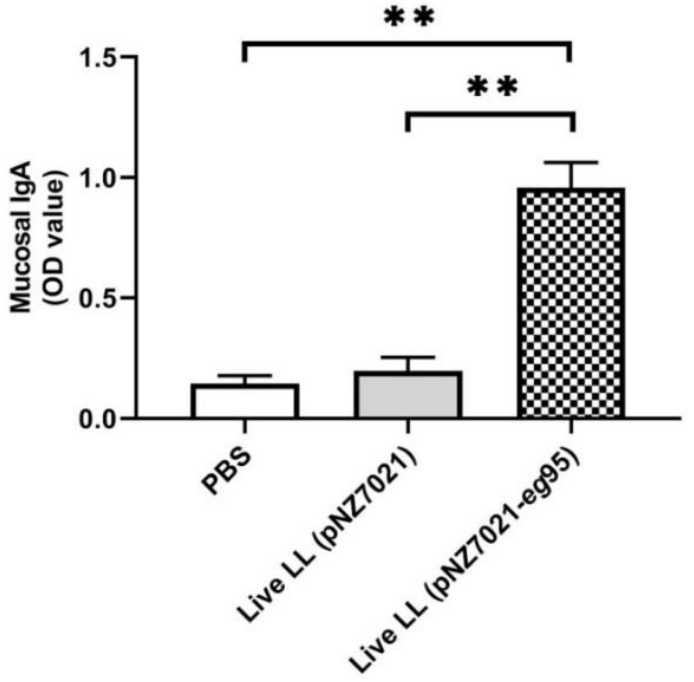

Fig. 5. Anti-EG95 sIgA antibody responses in mice orally immunized with PBS, L. lactis (pNZ7021), and live recombinant L. lactis (pNZ7021-eg95). Fecal samples were assessed for EG95-specific IgA by ELISA. Data are shown as mean \pm SD of duplicate experiments.

\section{DISCUSSION}

LAB expressing heterologous antigens is an attractive platform for vaccine delivery. Recombinant LAB was represented to stimulate systemic and mucosal immune responses ${ }^{[23]}$. Studies have shown that heat-killed probiotics, similar to live microorganisms, have beneficial effects on the host $^{[31-33]}$.

There are some reports on the successful trials of the surface antigen displaying $L$. lactis as vaccine carriers ${ }^{[25,26]}$. This form of expression has been

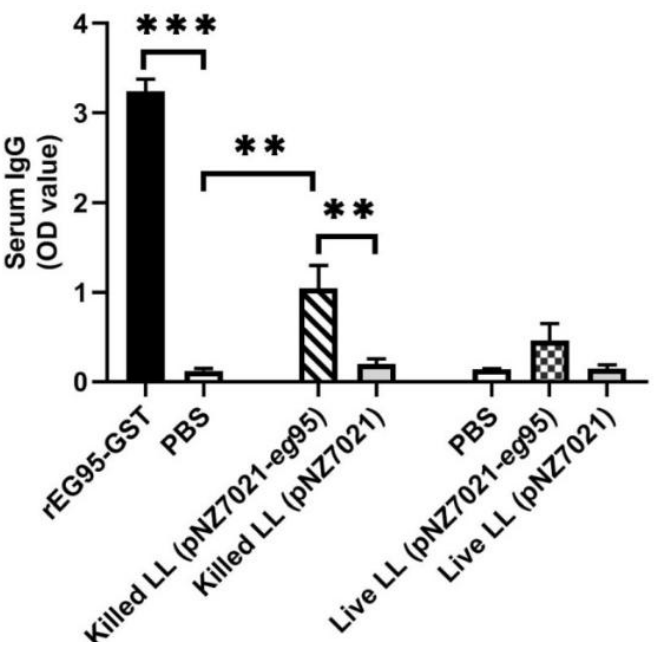

Fig. 6. Detection of EG95-specific total IgG in serum samples of all experimental BALB/c groups. A total of five mice from each group were tested in the ELISA test. Data are shown as mean \pm SD of duplicate experiments. considered advantageous for having better recognition by the immune system and probably evokes more robust immune responses. Therefore, the surface display in the LAB can be ideal and beneficial for vaccination compared to other forms ${ }^{[34-36]}$. For anchoring EG95 protein to the cell surface, we utilized Usp45 signal peptide at the N-terminal and the M6 cell-wall anchor at the C-terminal of the protein, and our results showed that EG95 could effectively be exhibited at the cell wall of L. lactis (Fig. 4).

The oral route of immunization can induce the mucosal immune responses; however, it is not necessarily effective as the subcutaneous route in the induction of systemic immunity. For determining the effective type of immunity, administration of live and heat-killed $L$. lactis bacteria to mice groups was performed as an immunization schedule.

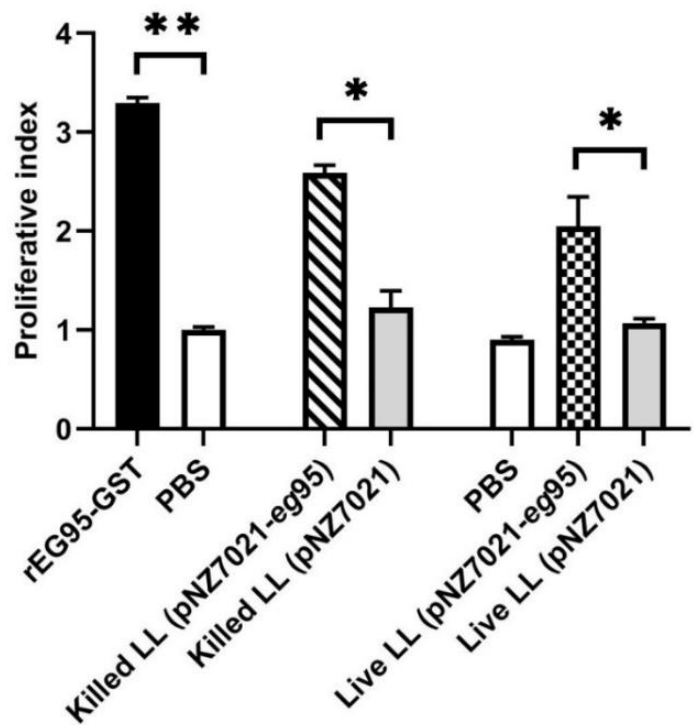

Fig. 7. Proliferative responses of murine splenocytes stimulated with EG95 antigen in vitro. The MTT assay was used to analyze splenocyte proliferation response towards EG95 antigen following 72-h stimulation with $10 \mu \mathrm{g} / \mathrm{ml}$ of purified rEG95 or $5 \mathrm{mg} / \mathrm{ml}$ of ConA as T cell mitogenic agent. The bars represent the mean OD values of splenocytes proliferation of immunized mice in each group.

Different antibody responses, including specific $\operatorname{IgG}$ subclasses, have been shown in parasitic infections ${ }^{[37,38]}$. Immunization of mice and sheep with oncosphere antigens, hydatid cyst fluid, and protoscoleces of E. granulosus could induce $\mathrm{IgG}$, $\mathrm{IgG} 1$, and $\operatorname{IgG} 2 \mathrm{a}$ responses ${ }^{[39-41]}$. Sheep vaccination using the EG95 vaccine in experimental trials produced the high levels of total $\operatorname{IgG}, \operatorname{IgG} 1$ and $\operatorname{IgG} 2$ antibodies $^{[42]}$. The specific anti-EG95 IgG and IgG2a antibodies increased by the EG95 DNA vaccination of $\mathrm{BALB} / \mathrm{c}$ mice ${ }^{[43]}$. In our study, although the total IgG 

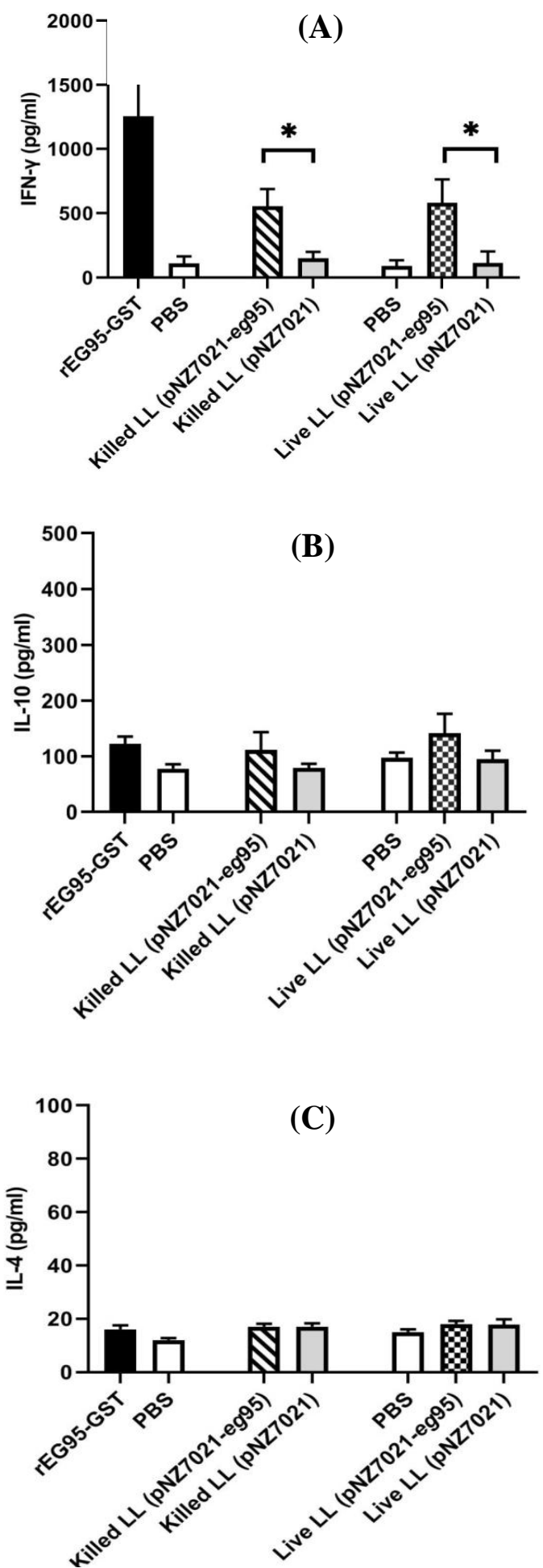

Fig. 8. Assessment of cytokine production in murine splenocytes stimulated with EG95 antigen in vitro. The splenocytes isolated from mice immunized with L. lactis strains or purified rEG95 protein were stimulated with $10 \mu \mathrm{g} / \mathrm{ml}$ of purified rEG95 or $5 \mathrm{mg} / \mathrm{ml}$ of ConA. Supernatants were collected after $72 \mathrm{~h}$ of stimulation. IFN- $\gamma$ (A), IL-10 (B), and IL4 (C) levels were measured by ELISA. Data are shown as mean \pm SD of duplicate experiments $(n=5)$. level in mice immunized with heat-killed L. lactis significantly increased compared to the control group, no significant differences were observed for $\operatorname{IgG}$ subclasses between the test and control groups. Moreover, serum IgG titers differed significantly between the mice immunized with the purified rEG95 and the mice vaccinated with killed and live recombinant L. lactis (pNZ7021-eg95).

We observed that the oral immunization of mice with live rL.lactis/pNZ7021-eg95 could lead to EG95specific SIgA production; however, it could not induce IgG antibody. On the other hand, subcutaneous immunization with heat-killed $L$. lactis expressing EG95 induced higher levels of IgG. Heat-killed $\mathrm{rL}$.lactis/pNZ7021-eg95 also showed another potential of this platform in vaccine designing without next downstream expensive preparation such as purification of protein. We examined this alternative form besides the oral live form, and the results showed that this model's systemic immune response was significant. Earlier studies have reported that the induction of $\operatorname{IgG}$ antibody against EG95 antigen correlates with protection against challenge infection with $E$. granulosus eggs in sheep that had been vaccinated with the EG95 vaccine ${ }^{[44]}$. On the other hand, oral immunization with the recombinant $L$. lactis expressing EG95 antigen can elevate mucosal immune responses $(\mathrm{s} \operatorname{Ig} \mathrm{A})$ and may confer intestinal protection against oncospheres in intermediate hosts infected by ingestion of parasite eggs. In general, regarding the infections that occur via the mucosal sites, an effective vaccine should be able to stimulate both mucosal and systemic immune responses ${ }^{[45]}$. Accordingly, the induction of $\operatorname{sIg} \mathrm{A}$ and serum $\operatorname{IgG}$ implies that the coadministration of two forms of the vaccine may be more effective against $\mathrm{CE}$ in intermediate hosts.

Following immunization with $L$. lactis-expressing EG95, the splenocytes were stimulated with rEG95 protein, and then splenocyte proliferation and cytokine production were evaluated. The results of our study indicated that the proliferative response in the mice group immunized with live and heat-killed rL.lactis/pNZ7021-eg95 remarkably increased compared to the control group. This result confirms the specific induction of cellular proliferation by the EG95 antigen. Also, we showed that the production of IFN- $\gamma$ was notably increased in both mice groups immunized with live and heat-killed rL.lactis/pNZ7021-eg95 compared to the control groups. Moreover, IFN- $\gamma$ levels differed significantly between the mice immunized with the purified rEG95 and those vaccinated with killed and live recombinant $L$. lactis (pNZ7021-eg95). However, IL-10 and IL4 levels were not statistically different between the immunized and 
control groups. An increase in the IFN- $\gamma /$ IL-10 ratio in the immunized mice may be a sign of protective immune responses. IFN- $\gamma$ demonstrates immunomodulatory effects by increasing antigen processing and presentation. An essential role of IFN- $\gamma$ is to identify and eliminate pathogens. Production of IFN- $\gamma$ also involved in Th1 differentiation ${ }^{[46]}$. Previous study have revealed both Th1 and Th2 immune responses in the human infected with hydatid cyst $^{[47]}$. A Th1 response relates to protective immunity, whereas a Th2 response results in CE susceptibility ${ }^{[48,49]}$. Th1 and Th2 immune responses have been demonstrated in the mice immunized with the EG95 genetic vaccine and then infected with E. granolosus protoscoleces. The level of Th1 cytokines significantly increased, while that of Th2 cytokines decreased after vaccination with the EG95 vaccine. A predominant Th1 response was associated with protection against secondary hydatidosis ${ }^{[50]}$.

It should be noted that due to the effective impact of the EG95 antigen on the oral route, its permanent use in livestock feeds and even feeding dogs with other protoscoleces-specific antigens by $L$. lactis delivery system, as a simple strategy for the creation of immunity in livestock and dogs, seems promising but more studies are needed to be conducted. It is also necessary to evaluate the immunogenicity and immunoprotection of recombinant $L$. lactis-expressing EG95 among intermediate hosts such as sheep by their challenging with $E$. granulosus eggs per oral or more. In this work, we performed a novel presentation of $E$. granulosus EG95 at the surface of L. lactis as an antigen carrier vehicle. Our results support that $L$. lactis expressing cell-surfaced EG95 antigen can be utilized as a new vaccine candidate against cystic hydatid disease.

\section{ACKNOWLEDGMENTS}

The present study was supported by Zanjan University of Medical Sciences, Zanjan, Iran through a grant (no. A-12-873-6). The authors greatly thank professor MW Lightowlers and Dr. CG Gauci at the University of Melbourne for providing EG95 protein and Dr. Negar Seyed at the Pasteur Institute of Iran for the technical guidance and constant support.

CONFLICT OF INTEREST. None declared.

\section{REFERENCES}

1. Craig PS, McManus DP, Lightowlers MW, Chabalgoity JA, Garcia HH, Gavidia CM, Gilman RH, Gonzalez AE, Lorca M, Naquira C, Nieto A, Schantz PM. Prevention and control of cystic echinococcosis. Lancet infectious disease 2007; 7(6): 385-394.

2. McManus DP, Zhang W, Li J, Bartley PB. Echinococcosis. The lancet 2003; 362(9392): 12951304.

3. Eckert J, Deplazes P. Biological, epidemiological, and clinical aspects of echinococcosis, a zoonosis of increasing concern. Clinical microbiology reviews 2004; 17(1): 107-135.

4. Cvejic D, Schneider C, Fourie J, de Vos C, Bonneau S, Bernachon N, Hellmann K. Efficacy of a single dose of milbemycin oxime/praziquantel combination tablets, Milpro®, against adult Echinococcus multilocularis in dogs and both adult and immature E. multilocularis in young cats. Parasitology research 2016; 115(3): 11951202.

5. Chow C, Gauci CG, Cowman AF, Lightowlers MW. A gene family expressing a host-protective antigen of Echinococcus granulosus. Molecular and biochemical parasitology 2001; 118(1): 83-88.

6. Chow C, Gauci CG, Cowman AF, Lightowlers MW. Echinococcus granulosus: oncosphere-specific transcription of genes encoding a host-protective antigen. Experimental parasitology 2004; 106(3-4): 183-186.

7. Lightowlers M, Lawrence S, Gauci C, Young J, Ralston M, Maas D, Heath D. Vaccination against hydatidosis using a defined recombinant antigen. Parasite immunology 1996; 18(9): 457-462.

8. Lightowlers $\mathrm{M}$, Jensen $\mathrm{O}$, Fernandez $\mathrm{E}$, Iriarte $\mathrm{J}$, Woollard D, Gauci C, Jenkins D, Heath D. Vaccination trials in Australia and Argentina confirm the effectiveness of the EG95 hydatid vaccine in sheep. International journal for parasitology 1999; 29(4): 531534.

9. LI ZJ, Wang YN, Qi W, Wei Z. Echinococcus granulosus 14-3-3 protein: a potential vaccine candidate against challenge with Echinococcus granulosus in mice. Biomedical and environmental sciences 2012; 25(3): 352-358.

10. Shi Z, Wang Y, Li Z, Li Z, Bo Y, Ma R, Zhao W. Cloning, expression, and protective immunity in mice of a gene encoding the diagnostic antigen P-29 of Echinococcus granulosus. Acta biochimica et biophysica sinica 2009; 41(1): 79-85.

11. Sun J, Wang Y, Li Z, Ma R, Ji H, Xiong Y, Wang Y, Li Z, Zhao W. Echinococcus granulosus: immunoprotection accompanyied by humoral and cytokine response against secondary hydatidosis in mice immunized with $\mathrm{rEg}$. Myophilin. Veterinary research communications 2011; 35(4): 193-200.

12. Behnsen J, Deriu E, Sassone-Corsi M, Raffatellu M. Probiotics: properties, examples, and specific applications. Cold spring harbor perspectives medicine 2013; 3(3): a010074.

13. Mercenier A, Muller-Alouf H, Grangette C. Lactic acid bacteria as live vaccines. Current issues in molecular biology 2000; 2: 17-26.

14. Nouaille S, Ribeiro LA, Miyoshi A, Pontes D, Le Loir Y, Oliveira SC, Langella P, Azevedo V. Heterologous 
protein production and delivery systems for Lactococcus lactis. Genetics and molecular research 2003; 2(1): 102-111.

15. Ma Y, Liu J, Hou J, Dong Y, Lu Y, Jin L, Cao R, Li T, $\mathrm{Wu}$ J. Oral administration of recombinant Lactococcus lactis expressing HSP65 and tandemly repeated P277 reduces the incidence of type I diabetes in non-obese diabetic mice. PloS one 2014; 9(8): e105701.

16. Bermúdez-Humarán LG, Nouaille $\mathrm{S}$, Zilberfarb V, Corthier G, Gruss A, Langella P, Issad T. Effects of intranasal administration of a leptin-secreting Lactococcus lactis recombinant on food intake, body weight, and immune response of mice. Appllied and environmental microbiology 2007; 73(16): 5300-5307.

17. Watterlot L, Rochat T, Sokol H, Cherbuy C, Bouloufa I, Lefèvre F, Gratadoux J-J, Honvo-Hueto E, Chilmonczyk S, Blugeon S, Corthier G, Lengella P, Bermudez-Humaran L. Intragastric administration of a superoxide dismutase-producing recombinant Lactobacillus casei BL23 strain attenuates DSS colitis in mice. International journal of food microbiology 2010; 144(1): 35-41.

18. Bermúdez-Humarán LG, Cortes-Perez NG, Lefèvre F, Guimarães V, Rabot S, Alcocer-Gonzalez JM, Gratadoux J-J, Rodriguez-Padilla C, Tamez-Guerra RS, Corthier G, Gruss A, Langella P. A novel mucosal vaccine based on live Lactococci expressing E7 antigen and IL-12 induces systemic and mucosal immune responses and protects mice against human papillomavirus type 16-induced tumors. Journal of immunology 2005; 175(11): 7297-7302.

19. Medina E, Guzmán CA. Use of live bacterial vaccine vectors for antigen delivery: potential and limitations. Vaccine 2001; 19(13-14): 1573-1580.

20. Cano-Garrido O, Seras-Franzoso J, Garcia-Fruitos E. Lactic acid bacteria: reviewing the potential of a promising delivery live vector for biomedical purposes. Microbial cell factories 2015; 14(1): 137.

21. Bohlul E, Hasanlou F, Taromchi AH, Nadri S. TRAILexpressing recombinant Lactococcus lactis induces apoptosis in human colon adenocarcinoma SW 480 and HCT 116 cells. Journal of applied microbiology 2019; 126(5): 1558-1567.

22. Perdigón G, Fuller R, Raya R. Lactic acid bacteria and their effect on the immune system. Current issues in intestinal microbiology 2001; 2(1): 27-42.

23. Wells J, Robinson K, Chamberlain L, Schofield K, Le Page R. Lactic acid bacteria as vaccine delivery vehicles. Antonie Van Leeuwenhoek 1996; 70(2-4): 317 330.

24. Ramasamy R, Yasawardena S, Zomer A, Venema G, Kok J, Leenhouts K. Immunogenicity of a malaria parasite antigen displayed by Lactococcus lactis in oral immunisations. Vaccine 2006; 24(18): 3900-3908.

25. Lim S, Jahanshiri F, Abdul Rahim R, Sekawi Z, Yusoff K. Surface display of respiratory syncytial virus glycoproteins in Lactococcus lactis NZ9000. Letters in applied microbioloogy 2010; 51(6): 658-664.

26. Cortes-Perez NG, Azevedo V, Alcocer-González JM, Rodriguez-Padilla C, Tamez-Guerra RS, Corthier G,
Gruss A, Langella P, Bermúdez-Humarán LG. Cellsurface display of E7 antigen from human papillomavirus type-16 in Lactococcus lactis and in Lactobacillus plantarum using a new cell-wall anchor from lactobacilli. Journal of drug targeting 2005; 13(2): 89-98.

27. Kuipers OP, de Ruyter PG, Kleerebezem M, de Vos WM. Quorum sensing-controlled gene expression in lactic acid bacteria. Journal of biotechnology 1998; 64(1): $15-21$

28. Wegkamp A, van Oorschot W, de Vos WM, Smid EJ. Characterization of the role of para-aminobenzoic acid biosynthesis in folate production by Lactococcus lactis. Appllied and environmental microbiology 2007; 73(8): 2673-2681.

29. Zhang HX, Qiu YY, Zhao YH, Liu XT, Liu M, Yu AL. Immunogenicity of oral vaccination with Lactococcus lactis derived vaccine candidate antigen (UreB) of Helicobacter pylori fused with the human interleukin 2 as adjuvant. Molecular and cellular probes 2014; 28(1): 25-30.

30. Perez C, Eichwald C, Burrone O, De Mendoza D. Rotavirus vp7 antigen produced by Lactococcus lactis induces neutralizing antibodies in mice. Journal of applied microbiology 2005; 99(5): 1158-1164.

31. Maruyama M, Abe R, Shimono T, Iwabuchi N, Abe F, Xiao JZ. The effects of non-viable Lactobacillus on immune function in the elderly: a randomised, doubleblind, placebo-controlled study. International journal of food sciences nutrition 2016; 67(1): 67-73.

32. Ting WJ, Kuo WW, Hsieh DJY, Yeh YL, Day CH, Chen YH, Chen RJ, Padma VV, Chen YH, Huang CY. Heat killed Lactobacillus reuteri GMNL-263 reduces fibrosis effects on the liver and heart in high fat diethamsters via TGF- $\beta$ suppression. International journal of molecular sciences 2015; 16(10): 25881-25896.

33. Torii S, Torii A, Itoh K, Urisu A, Terada A, Fujisawa T, Yamada K, Suzuki H, Ishida Y, Nakamura F, Kanzato H, Sawada D, Nonaka A, Hatanaka M, Fujiwara S. Effects of oral administration of Lactobacillus acidophilus L-92 on the symptoms and serum markers of atopic dermatitis in children. International archives of allergy and immunology 2011; 154(3): 236-245.

34. Bermúdez-Humarán LG, Cortes-Perez NG, Le Loir Y, Alcocer-González JM, Tamez-Guerra RS, de Oca-Luna $\mathrm{RM}$, Langella $\mathrm{P}$. An inducible surface presentation system improves cellular immunity against human papillomavirus type $16 \mathrm{E} 7$ antigen in mice after nasal administration with recombinant lactococci. Journal of medical microbiology 2004; 53(5): 427-433.

35. Leclerc C, Charbit A, Molla A, Hofnung M. Antibody response to a foreign epitope expressed at the surface of recombinant bacteria: importance of the route of immunization. Vaccine 1989; 7(3): 242-248.

36. Georgiou G, Stathopoulos C, Daugherty PS, Nayak AR, Iverson BL, Curtiss III R. Display of heterologous proteins on the surface of microorganisms: from the screening of combinatorial libraries to live recombinant vaccines. Nature biotechnology 1997; 15(1): 29-34. 
37. Mazza G, Dunne D, Butterworth A. Antibody isotype responses to the Schistosoma mansoni schistosomulum in the CBA/N mouse induced by different stages of the parasite life cycle. Parasite immunology 1990; 12(4-5): 529-543.

38. Atmadja AK, Atkinson R, Sartono E, Partono F, Yazdanbakhsh M, Maizels RM. Differential decline in filaria-specific IgG1, IgG4, and IgE antibodies in Brugia malayi-infected patients after diethylcarbamazine chemotherapy. Journal of infection disease 1995; 172(6): 1567-1572.

39. Al-Qaoud KM, Abdel-Hafez SK. Humoral and cytokine response during protection of mice against secondary hydatidosis caused by Echinococcus granulosus. Parasitology research 2005; 98(1): 54-60.

40. Yong W, Heath D, Van Knapen F. Comparison of cestode antigens in an enzyme-linked immunosorbent assay for the diagnosis of Echinococcus granulosus, Taenia hydatigena and $T$ ovis infections. in sheep. Research in veterinary sciences $1984 ;$ 36(1): 24-31.

41. Zhang W, You H, Li J, Zhang Z, Turson G, Aili H, Wang $\mathbf{J}$, Mcmanus DP. Immunoglobulin profiles in a murine intermediate host model of resistance for Echinococcus granulosus infection. Parasite immunology 2003; 25(3): 161-168.

42. Woollard D, Gauci C, Heath D, Lightowlers M. Epitope specificities and antibody responses to the EG95 hydatid vaccine. Parasite immunology 1998; 20(11): 535-540.

43. Lin R, Ding J, Lu X, Wang X, Wei X, Wang Y, Wen H. Transient expression of Echinococcus granulosus Eg95 DNA vaccine and induction of immune response in mice. Chinese journal of parasitology \& parasitic diseases 2004; 22(4): 204-208.
44. Heath D, Jensen O, Lightowlers M. Progress in control of hydatidosis using vaccination-a review of formulation and delivery of the vaccine and recommendations for practical use in control programmes. Acta tropica 2003; 85(2): 133-143.

45. Miquel-Clopés A, Bentley E, Stewart J, Carding S. Mucosal vaccines and technology. Clinical and experimental immunology 2019; 196(2): 205-214.

46. Kak G, Raza M, Tiwari BK. Interferon-gamma (IFN- $\gamma$ ): exploring its implications in infectious diseases. Biomolecular concepts 2018; 9(1): 64-79.

47. Rigano R, Profumo E, Di Felice G, Ortona E, Teggi A, Siracusano A. In vitro production of cytokines by peripheral blood mononuclear cells from hydatid patients. Clinical and experimental immunology 1995; 99(3): 433-439.

48. Rigano R, Profumo E, Ioppolo S, Notargiacomo S, Teggi A, Siracusano A. Cytokine patterns in seropositive and seronegative patients with Echinococcus granulosus infection. Immunology letters 1998; 64(1): 5-8.

49. Mezioug D, Touil-Boukoffa C. Cytokine profile in human hydatidosis: possible role in the immunosurveillance of patients infected with Echinococcus granulosus. Parasite 2009; 16(1): 57-64.

50. Ding JB, Ma XM, Wei XL, Jia HY, Mamuti W, Lin RY, Hou M, Wen H. Th1 and Th2 cytokines in mice infected with Echinococcus granulosus and immunized with Eg95 genetic vaccine. Cell biology international 2008; 32(3): S48-S49. 


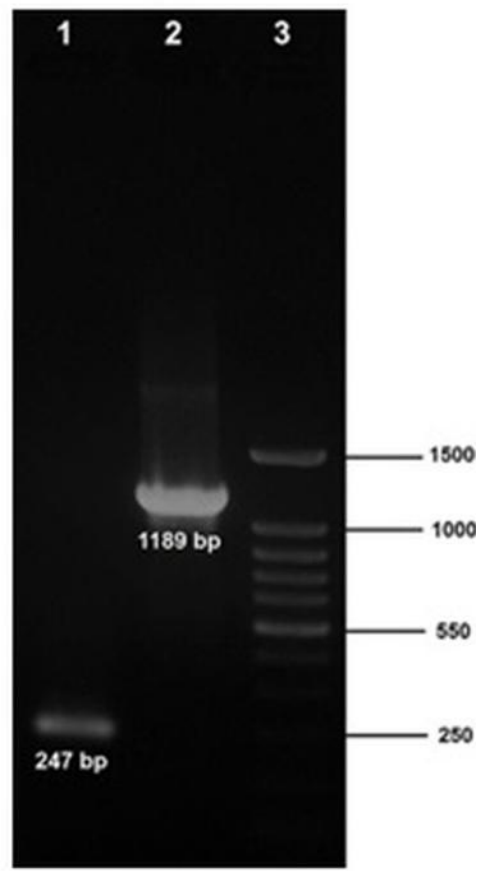

A

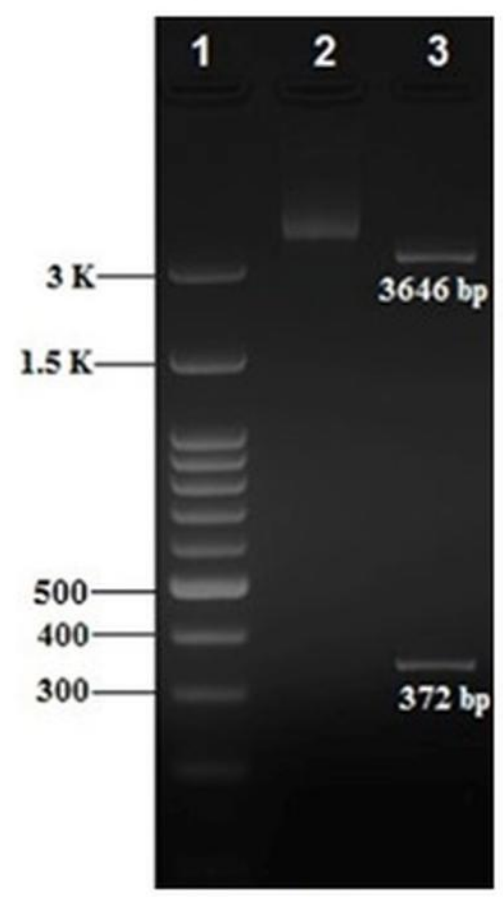

B

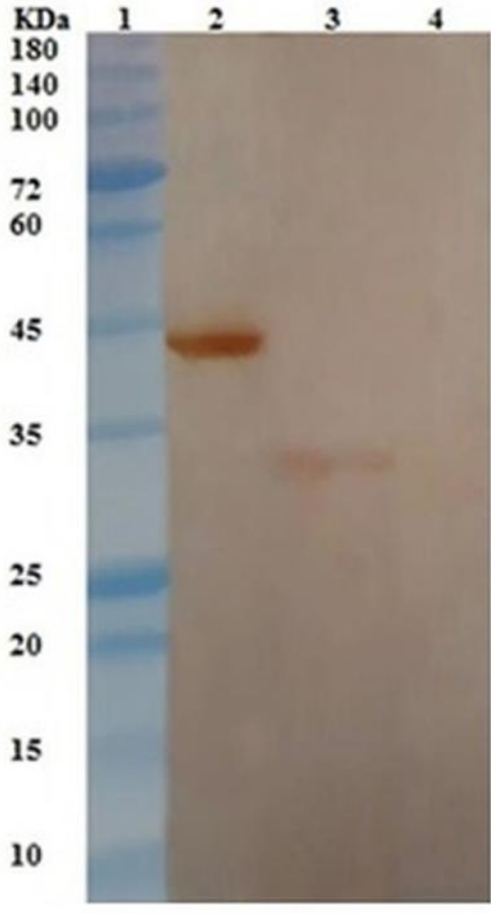

C

Supplementary Fig. S1. Identification of recombinant plasmid pNZ7021-eg95 and detection of the EG95 protein expression. (A) PCR amplification of eg95 fragment. Lane 1, PCR product from empty pNZ7021 vector (247 bp); lane 2, PCR product from recombinant pNZ7021-eg95 vector (1189 bp); lane 3, DNA ladder (100 bp). (B) Restriction digestion analysis of the pNZ7021-eg95 expression vector. Lane 1, DNA ladder (100 bp); lane 2, undigested pNZ7021-eg95 vector; lane 3, BglII digested pNZ7021-eg95 expression vector. (C) EG95 identity confirmation through Western blotting. Lane 1, protein MW marker; lane 2, purified rEG95-GST protein (43.5 kDa; positive control); lane3, recombinant L. lactis NZ9000 strain containing pNZ7021-eg95 vector ( 33 kDa); lane 4, L. lactis NZ9000 strain containing empty pNZ7021 plasmid (negative control). 

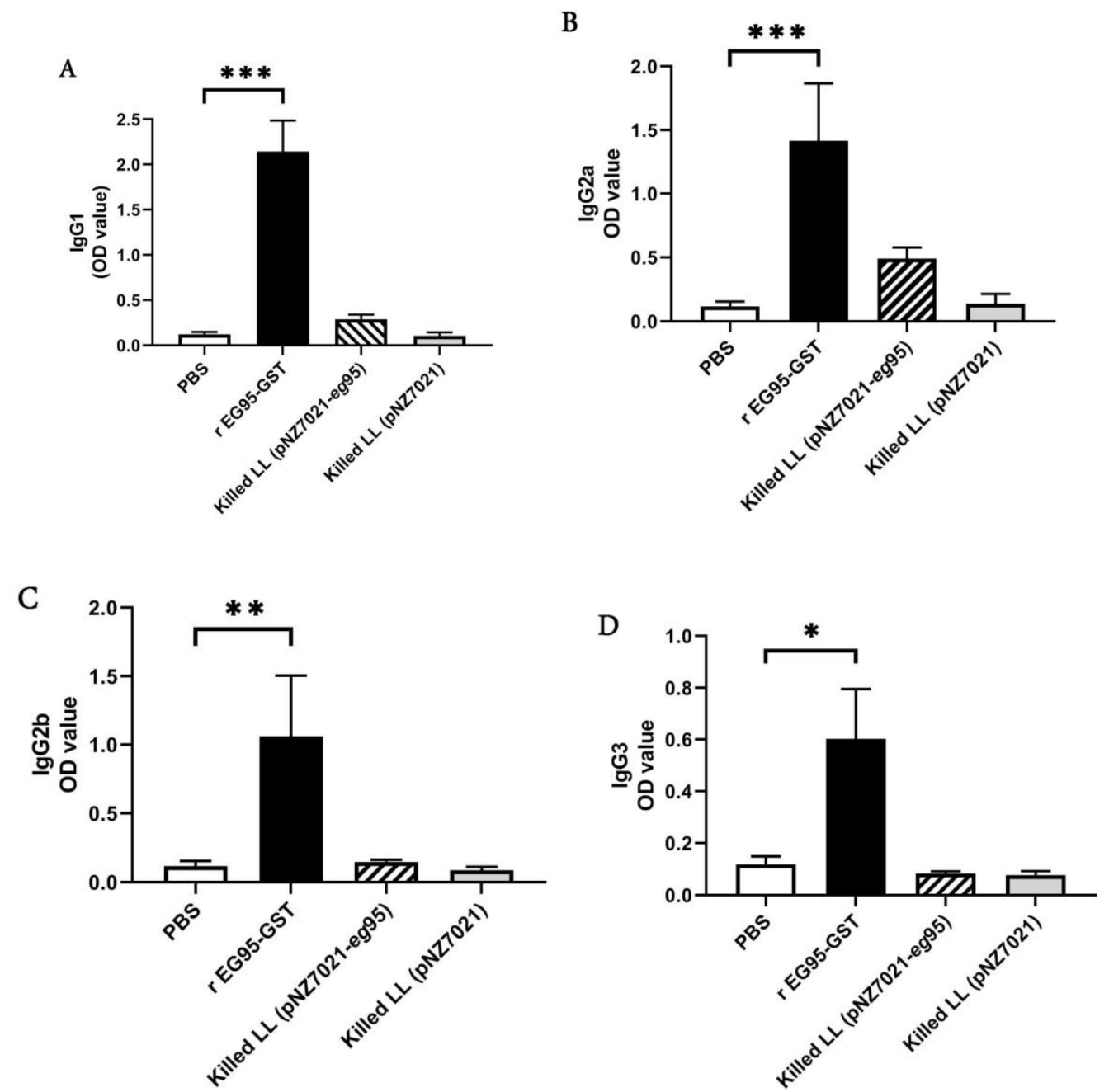

Supplementary Fig. S2. Assessment of EG95-specific IgG subclasses in mice subcutaneously immunized with PBS and killed recombinants L. lactis (pNZ7021-eg95) and L. lactis (pNZ7021). IgG1 (A), IgG2a (B), IgG2b (C), and IgG3 (D) levels were measured by ELISA. Data are shown as mean \pm SD of duplicate experiments 